\title{
Making it Work for Everyone: Developing Flexible Digital Clinical Communication Modules for Health Disciplines in an Australian Context
}

\author{
Nayia Cominos \\ Flinders University, Nayia.cominos@flinders.edu.au \\ Kerry Thoirs \\ University of S. Australia, kerry.thoirs@unisa.edu.au \\ Rowena Harper \\ University of South Australia, rowena.harper@unisa.edu.au \\ Giordana Cross \\ University of South Australia, giordana.cross@unisa.edu.au \\ Megan Cooper \\ Flinders University, megan.cooper@flinders.edu.au
}

Follow this and additional works at: https://nsuworks.nova.edu/ijahsp

Part of the Health and Physical Education Commons, Higher Education Commons, Interprofessional Education Commons, and the Language and Literacy Education Commons

\section{Recommended Citation}

Cominos N, Thoirs K, Harper R, Cross G, Cooper M. Making it Work for Everyone: Developing Flexible Digital Clinical Communication Modules for Health Disciplines in an Australian Context. The Internet Journal of Allied Health Sciences and Practice. 2021 Jan 01;19(3), Article 13.

This Manuscript is brought to you for free and open access by the College of Health Care Sciences at NSUWorks. It has been accepted for inclusion in Internet Journal of Allied Health Sciences and Practice by an authorized editor of NSUWorks. For more information, please contact nsuworks@nova.edu. 


\title{
Making it Work for Everyone: Developing Flexible Digital Clinical Communication Modules for Health Disciplines in an Australian Context
}

\begin{abstract}
Purpose: This paper discusses an innovative multi-disciplinary approach to the development and evaluation of flexible, digital clinical communication learning resources to support students in twelve health disciplines to develop clinical communication skills in preparation for their clinical placements. Methods: A modified Delphi survey was sent to all stakeholders in the Division of Health Sciences to identify the most important communication skills from the list of 61 communication skills identified by Bachmann et al in 2013. Lecturers, clinical educators, clinicians, and students were invited to rate the importance of each skill. Results: A set of digital resources was created for teaching clinical communication to students across all years and disciplines and for use by clinical educators in the Division to prepare students for clinical placement. In addition, an effective methodology for course development, involving broad consultation and multi-disciplinary development teams comprised of clinicians and other educational experts, was developed. The resources were implemented in two disciplines, podiatry and midwifery, and evaluated pre- and post-placement using a qualitative and quantitative method developed with the course coordinators. Conclusions: There are identifiable clinical communication skills which are applicable across numerous health disciplines and as for other learnable skills, teaching can be enhanced by breaking them down into specific, demonstrable elements which students can observe and practice. Using the pedagogy and methods outlined in the paper, students demonstrated increased awareness of the importance of communication in the clinical context, and the capacity to evaluate their performance of those skills.
\end{abstract}

\section{Author Bio(s)}

Nayia Cominos PhD is a researcher, educator, and consultant in communication, literacy, curriculum, and linguistics. She is a Senior Lecturer in Health Professions Education in the College of Medicine and Public Health, Flinders University, in the Master of Clinical Education, and teaching specialist in curricula, assessment, and online educational design.

Kerry Thoirs PhD previous Associate Head of School (Academic) in the School of Health Sciences at the University of South Australia. Kerry has held leadership positions in both the clinical and academic sectors, with experience in curriculum development and an interest in flexible delivery. Her discipline area is Medical Radiations.

Professor Rowena Harper is Director of the Centre for Learning and Teaching at Edith Cowan University. She has held senior teaching and leadership roles in Australian higher education and has worked to foster whole-of-institution approaches to both equity and excellence, including President of the Association for Academic Language and Learning.

Giordana Cross PhD is a Senior Lecturer in Dietetics in UniSA Clinical \& Health Sciences at the University of South Australia. She is a practicing clinician and former Program Director, lecturing in Therapeutics, Nutrition and Exercise, and Food Safety Regulation, and is a member of the Dietetic Association of Australia.

Megan Cooper $\mathrm{PhD}$ is a registered midwife, researcher, and senior lecturer in Midwifery at Flinders University. She has published extensively on water immersion and midwifery professional practice. She is an active member of the Australian College of Midwives and has been the Policy and Political Coordinator since 2017. 


\section{Acknowledgements}

This research contributed to a Master of Health Professional Education study at the University of Notre Dame Australia under the supervision of Professor Chris Hackett PhD and Associate Professor Elina Tor PhD. We would also like to acknowledge Dr Hayley Uden, the course coordinator of Podiatry, Jane Coffee, and Anne Lonie for her work on the resource website. 


\title{
IJAHSP \\ The Internet Joutnal of Allied Health Sciences and Practice
}

Dedicated to allied health professional practice and education

Vol. 19 No. 3 ISSN 1540-580X

\section{Making it Work for Everyone: Developing Flexible Digital Clinical Communication Modules for Health Disciplines in an Australian Context}

\author{
Nayia Cominos ${ }^{1}$ \\ Kerry Thoirs ${ }^{2}$ \\ Rowena Harper ${ }^{2}$ \\ Giordana Cross ${ }^{2}$ \\ Megan Cooper ${ }^{1}$ \\ 1. Flinders University \\ 2. University of S. Australia
}

Australia

\begin{abstract}
Purpose: This paper discusses an innovative multi-disciplinary approach to the development and evaluation of flexible, digital clinical communication learning resources to support students in twelve health disciplines to develop clinical communication skills in preparation for their clinical placements. Methods: A modified Delphi survey was sent to all stakeholders in the Division of Health Sciences to identify the most important communication skills from the list of 61 communication skills identified by Bachmann et al in 2013. Lecturers, clinical educators, clinicians, and students were invited to rate the importance of each skill. Results: A set of digital resources was created for teaching clinical communication to students across all years and disciplines and for use by clinical educators in the Division to prepare students for clinical placement. In addition, an effective methodology for course development, involving broad consultation and multi-disciplinary development teams comprised of clinicians and other educational experts, was developed. The resources were implemented in two disciplines, podiatry and midwifery, and evaluated pre- and post-placement using a qualitative and quantitative method developed with the course coordinators. Conclusions: There are identifiable clinical communication skills which are applicable across numerous health disciplines and as for other learnable skills, teaching can be enhanced by breaking them down into specific, demonstrable elements which students can observe and practice. Using the pedagogy and methods outlined in the paper, students demonstrated increased awareness of the importance of communication in the clinical context, and the capacity to evaluate their performance of those skills.
\end{abstract}

Keywords: communication, language, literacy, cross-disciplinary, simulation training 


\section{INTRODUCTION}

In clinical contexts, ineffective communication is a leading factor in unintentional harm to patients, and is a common issue raised in patient complaints. ${ }^{1,2}$ This can be due to an individual's lack of communication skills with patients, but is also frequently related to poor communication between health teams ${ }^{3}$, particularly when information is exchanged in formal and informal clinical handovers. ${ }^{3,4}$ Good communication skills are key in managing quality and safety in clinical contexts. ${ }^{5}$ In clinical education, it is therefore critical that students develop effective communication, so they can deliver optimal patient/client-centered care.

A key mechanism for communication development in the healthcare professions is the clinical placement - an integral part of the educational process for developing and ensuring competence and safe practice. It provides a supervised environment for students to apply their classroom-based knowledge to real life, often in complex and challenging situations. Verbal, non-verbal and written clinical communication skills have been deemed as an important characteristic for students to have prior to clinical placement by clinical educators. ${ }^{6}$ Moreover, evidence suggests that clinical placement providers are more willing to offer clinical training for students if they have well-developed communication skills. ${ }^{7}$ It is critical, then, for clinical education programs to begin developing students' communication prior to their first placements and build those skills over the duration of their training. This may improve student access to clinical placements and potentially improve both learning and performance.

In our institution, we teach students across multiple healthcare disciplines. Teaching clinical communication presents unique challenges due to its combination of technical complexity, emotional and non-verbal components, and the cultural and linguistic diversity of patient/clients and healthcare professionals. This was confirmed in our institution following feedback from students who were preparing for roles as health professionals and their educators in the clinical placements (clinical educators). In response, a multi-disciplinary working party of clinical educators and language and literacy specialists was formed to explore more effective ways of preparing students to communicate with patients/clients, other health professionals, and their clinical educators. Four important considerations guided this exploration: 1)to raise student awareness of clinical communication skills; 2) the commonality of clinical communication skills across a range of clinical health professions; 3 ) cost-effective and time-efficient teaching approach with alignment to the University's Digital Learning Strategy 2015-2020, to deliver an engaging and digitally enriched curriculum to students; and 4) to facilitate flexibility and applicability to multiple health professions regardless of teaching mode. ${ }^{8} \mathrm{It}$ was decided that a suite of digital clinical communication teaching resources would be developed. It was envisaged that these resources could be adapted for digitally enriched curricula for different health disciplines, in different settings, and using different teaching methods.

This paper aims to describe the development, implementation, and evaluation of digital teaching and learning resources to teach clinical communication skills across two very different student groups: podiatry students and midwifery students. These groups differed by profession, teaching pedagogies, year levels, course length, and level of clinical experience.

\section{METHODS}

\section{Development of Learning Objectives}

The work by Bachmann et al. ${ }^{9}$ was drawn on identify specific communication skills that were most critical prior to clinical placement. ${ }^{9}$ They used a Delphi process (involving 121 clinical communication experts from 15 professional fields and 16 European countries) to generate consensus on a list of 61 core clinical communication objectives. These covered three domains: communication with patients, intra- and interpersonal communication, and communication in health care teams.

A modified Delphi process was used to consult with stakeholders of health disciplines in our institution to identify the most important skills from this list. Lecturers, clinical educators, clinicians, and students were invited to rate the importance of each skill for graduates in their discipline and identify when each skill should be introduced into the curriculum. There were sixty-two respondents to the survey across 13 discipline areas. Of these, $59 \%$ identified as lecturers, $36 \%$ identified as clinical educators, and $41 \%$ identified as clinicians (staff could identify with more than one role). There were no recent graduate responses (Appendix 1).

Three skills were clearly identified as critical, all within the domain of communicating with patients:

1. adapts own communication to the level of understanding and language of the patient, avoiding jargon.

2. uses techniques to build up and maintain rapport and an empathetic relationship and ensures that the patient feels attended and listened to.

3 relates to the patient respectfully including ensuring confidentiality, privacy and autonomy and recognizing the patient as a partner in shaping a relationship.

These three skills were also identified as needing to be introduced to students prior to embarking on their first clinical placement.

( The Internet Journal of Allied Health Sciences and Practice, 2021 


\section{Development of Digital Learning Resources}

An iterative process was used to develop the online learning modules, drawing on clinical educators, language and literacy experts, and audio-visual specialists.

The core resources were a collection of short video vignettes, ranging from three to seven minutes, and scripted to illustrate learning objectives and common clinical experiences of students. The vignettes were situated in a range of disciplines, representing a diversity of clinicians and patients/clients. Each vignette covered an important phase of clinical interaction with patients/clients which was common across health professions (see Appendix 2), thereby being relevant to teach communication skills across different health professions even when the scenario depicted a situation representing a profession different to the target student group. For each vignette, two versions of the videos were produced: one showing less effective communication, and the other showing more effective communication. The terms "best" or "ideal" were deliberately avoided to describe the second version, to explicitly recognise that while there are identifiable skills which promote effective communication, these are always context dependant, so some may be more utilised in one situation rather than another.

Two language and literacy specialists unpacked the three skills into six specific, observable, and teachable elements to create rubrics for helping students and teachers identify and attend to relevant behavioural modelling in the resources. These elements were body language (reading it, responding to it, and using it), words and phrases (interpreting, selecting, and adapting them), reflective listening, proxemics, voice, and the use of supporting materials (e.g., handouts, notes, equipment). Staged levels of development were mapped to the four levels of Miller's pyramid, identifying how students' competence in each objective could be demonstrated at each level (figure 1). ${ }^{10}$ Staging the objectives in this way provided a means to plan and scaffold student development across lessons, courses, or year levels, allowing for a potentially programmatic approach. The use of different verbs in the rubrics at each level (drawn from Bloom's Taxonomy ${ }^{11}$ ) also allowed educators to align the learning plans more clearly to their existing course learning objectives and choose the most appropriate lesson plan for their context.

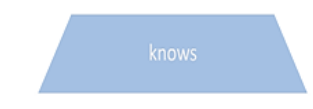

Knows

Student demonstrates awareness of each aspect of communication

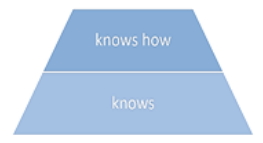

Knows how Student identifies how each aspect of communication affects the success of observed clinical interactions

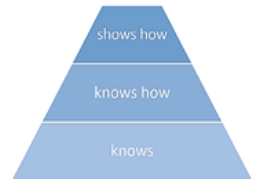

Shows how Student practises and reflects on their own use of each aspect of communication in role-play or clinical simulation

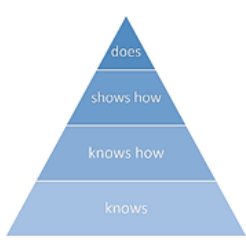

Does Student effectively uses each aspect of communication in a clinical setting

Figure 1: Miller's pyramid stages and corresponding clinical communication learning outcomes

Clinicians from twelve disciplines were invited to write communication scenarios which incorporated one or more of the skills and elements based on their clinical experience. These scripts formed the basis of a series of short videos produced by the University's audio-visual team, involving professional actors and staff members as cast members. To support integration of the videos into program curricula, the language and literacy team worked with a group of three clinical educators to create teaching and learning packs and additional resources such as preparatory quizzes and links to other useful materials. The resources were centralised on the University's Learning Management System. ${ }^{12}$ Search matrices were created (to allow educators to find relevant resources), and workshops promoting the resources were conducted. Following the workshops, two teachers, one each from the podiatry and midwifery disciplines, offered to work in partnership with the development team to adapt, introduce and evaluate the resources into their established curricula.

Together, the teachers and language and literacy specialists created teaching packs based on the videos and rubrics, containing lesson plans, student activities, and related learning resources. They were designed to be modularised, so they could be adapted to the level of experience of the teachers, the time available for teaching, and the delivery mode: face-to-face, blended, and fully online. Each teaching pack was structured to provide an overview of the learning objectives, the aims and rationale of the modules, the "teacher preparation" needed before using the modules, a sequenced plan for classroom implementation, and a teacher reflection guide to help identify what worked and what did not. Although curricula, professions, and year levels of the two professions were different, there were common aims in using the resources to present the elements of communication, to improve 
student awareness and understanding of the importance of clinical communication, and to give the students an opportunity to practice these skills in the classroom.

\section{Integration and Evaluation of Learning Modules in Podiatry Teaching}

Podiatry students at UniSA study an undergraduate degree over four years. The degree integrates experiential learning through practical and clinical experiences from its second year in the University's podiatry clinic and clinical placements in community and hospital podiatry settings. The podiatry teacher integrated the learning modules into a communication course which ran in the third year of the degree in 2017, when students had previous experience of some clinical practice at the University's podiatry clinics. The podiatry teacher worked with a language and literacy specialist to discuss the purpose of the communication, the most appropriate resources to use and methods to meaningfully integrate these resources into their teaching. They also worked together to design and develop an evaluation and feedback framework.

A Foundation Quiz (appendix 3) and videos were drawn from the resources. The Foundation Quiz was given to the students prior to commencing the course as a discussion starting point for the students in the first lesson. Students were encouraged to give their opinions using examples from their clinical placement experiences. The videos were progressively included in three sessions at the beginning of the course over three consecutive days, and students were able to access them between sessions. The videos were used in a variety of ways: as an introduction to a skill set for class discussion, part of in-class activities, such as role-playing and critique, annotated by students individually using online software, following directives from the educator to identify problematic and/or effective communication, prior to attending class for in-class discussions, and as examples following readings on communication. Later in the course, the videos were used again. This, time students worked in groups to review and annotate different videos which included communication interactions involving podiatrists as well as other health professionals and presented their findings to the class. The teacher included a vignette assessment task at the end of the course, in which the students had to produce their own video scenarios demonstrating effective and less effective communication, based on the same principles as the clinical communication video resources. These learning activities were aligned with the learning module teaching guide and the "shows how" rubric.

All students attending the workshops were invited to complete a non-compulsory, anonymous survey at the end of the course to provide feedback on the resources and their use in class. Students were asked to rate four resources/activities used in the workshops (foundation quiz, video resources, annotation tool, vignette assignment) on a 5-point non-weighted scale of 1 to 5 to indicate their agreement with the following statements:

1. The activity was relevant to communication in clinical practice

2. I found the activity engaging

3. The activity was useful in preparing me for communicating in the clinical setting

4. As a result of the learning activity, I am more confident in engaging in communication in the clinical setting

5. I found the learning activity challenging

\section{Integration and Evaluation of Learning Modules in Midwifery Teaching}

Midwifery students at UniSA study an undergraduate degree over three years. The overall pedagogy is experiential and InquiryBased Learning (IBL), both of which encourage reflection and student initiative. The resources developed were adapted for use in a communication workshop in a first-year, foundational midwifery course prior to the students' first clinical placement in 2017. The workshop focused on "rapidly building rapport." Like podiatry, the students completed the foundation quiz prior to the workshop in addition to being offered the opportunity to rate their communication skills against a range of predefined questions.-Learning activities were adapted to align with the learning module teaching guide and the "knows how" rubric (which included midwifery examples).

The workshop began with students brainstorming "communication" in small groups. The students were then introduced to the rubric and a role-play activity based on everyday communication (i.e., giving directions and sharing good news). Students used the rubric to provide feedback to each other about the communication exchange with this improving awareness of communication elements such as proxemics and body language. Following class discussion, the importance of the communication elements was reiterated prior to the students watching video A (less effective communication). During this, students took notes individually, then had a group discussion which prompted them to draw on their new-found understanding of the elements of communication and language. This was repeated with video $B$ (more effective communication). Students then had the opportunity to apply their new skills and understanding of communication by engaging in history-taking simulation within their groups. Using the same rubric, they provided feedback to each other and were able to draw on the teachers for assistance or clarification. 
Students attending the workshop were invited to completed non-compulsory and anonymous pre- and post-workshop and postplacement surveys. Students were asked to rate five activities used in the workshops scale of 1 to 5 to indicate their agreement with the following statements:

1. The activity was relevant to communication in clinical practice

2. I found the activity engaging

3. The activity was useful in preparing me for communicating in the clinical setting

4. As a result of the learning activity, I am more confident in engaging in communication in the clinical setting

5. I found the learning activity challenging

Students were also asked to self-evaluate their awareness of each communication element, and their knowledge of how to address those elements when communicating in the clinical setting using a non-weighted 5-point scale.

\section{Teacher Feedback}

Both the podiatry and midwifery teachers were asked to provide feedback on the learning modules in individual interviews undertaken by an independent interviewer.

\section{RESULTS}

\section{Evaluation of Podiatry Learning Resources}

Twenty-two of the 26 students in the Podiatry class responded to the evaluation survey.

The videos were rated highest for engagement, usefulness, and increased confidence. They were also highly rated, second only to the vignettes, for relevance and challenge (figure 2). The videos and vignette assignment were rated as more challenging than the quiz and annotation tool. An explanation for this would be that the videos required active input from the students and were integrated into several activities which included independent learning and role play.

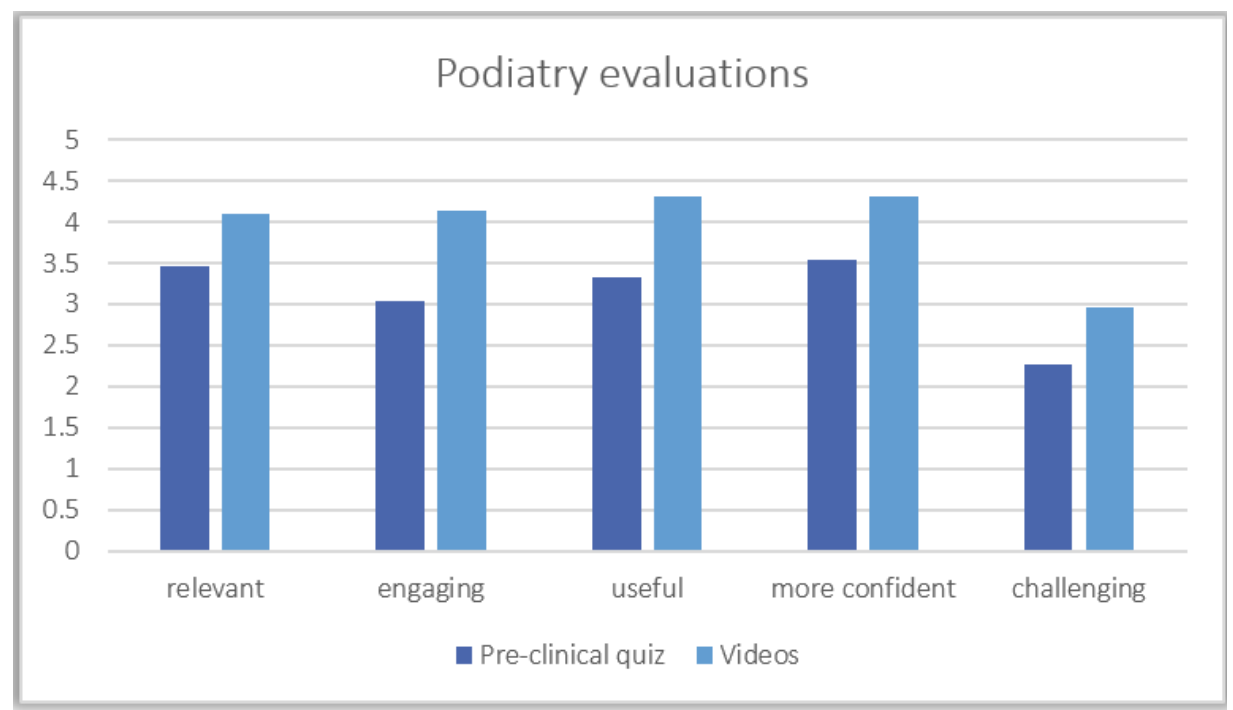

Figure 2: Results of Podiatry student survey responses in relation to the clinical communication resources

\section{Evaluation in Midwifery}

Sixty-eight of the 70 students in the Midwifery workshop responded to the pre-workshop evaluation survey, and sixty-three to the post-workshop and placement evaluation survey. Self-evaluation data identified how midwifery students perceived the value of the clinical communication resources used in the communication workshop. The quiz was not evaluated, as this activity was done in a different and separate tutorial.

Overall, students rated the workshop activities highly on Likert scales of strongly disagree (1) to strongly agree (5) as depicted in figure 3. The activities are presented in the same order as they occurred in the workshop, beginning with the everyday conversation 
roleplays, and ending with taking a handheld history. The videos rated highly on all questions, except whether the activity was challenging. The students' ratings increased with each subsequent activity.

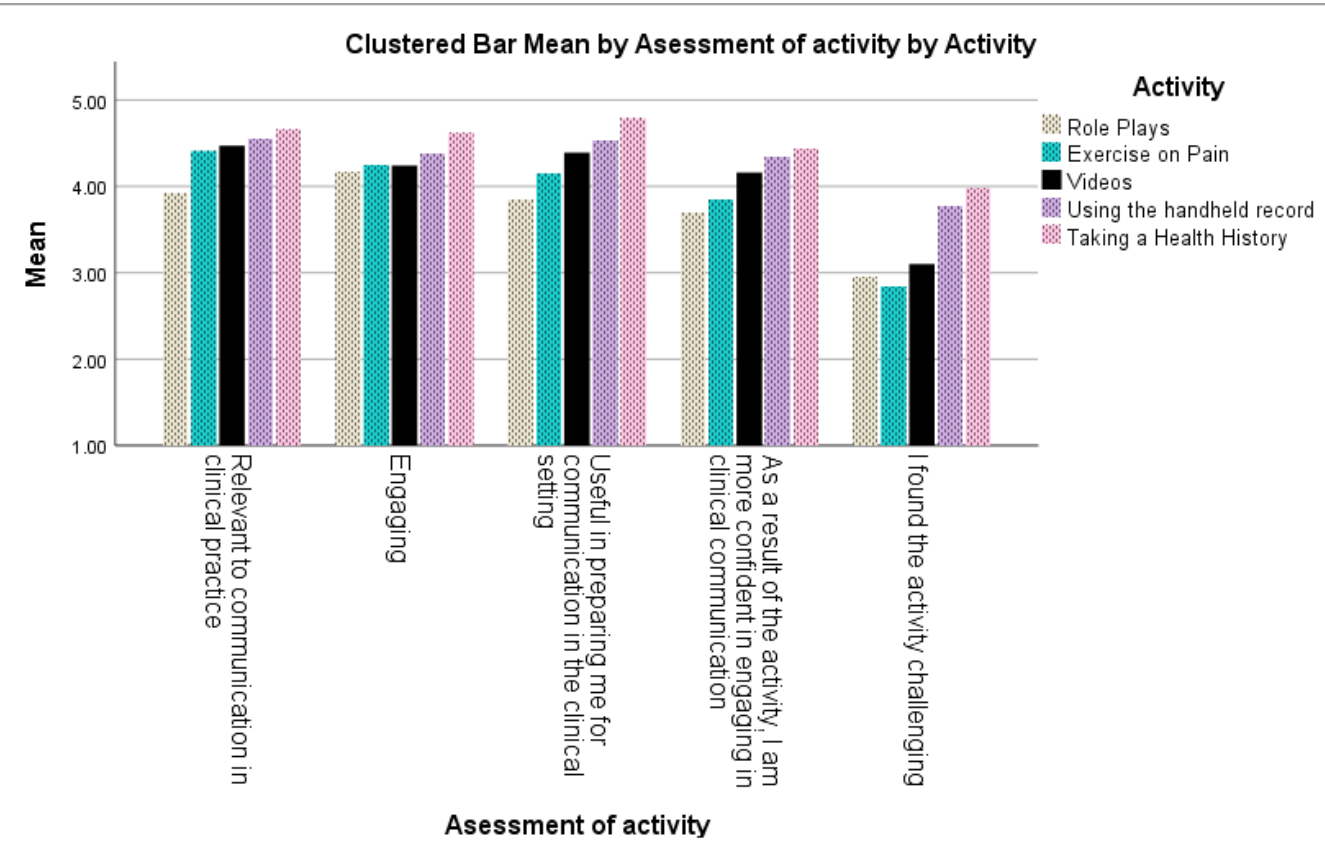

Figure 3: Midwifery student self-evaluation for workshop activities

There were improvements in the students' self-assessed awareness of communication elements across each subsequent time point. Figure 4 depicts this change (with respect to proxemics in communication as an example). A relatively large shift in awareness was noted from pre- to post-workshop and a smaller increase post-clinical placement.

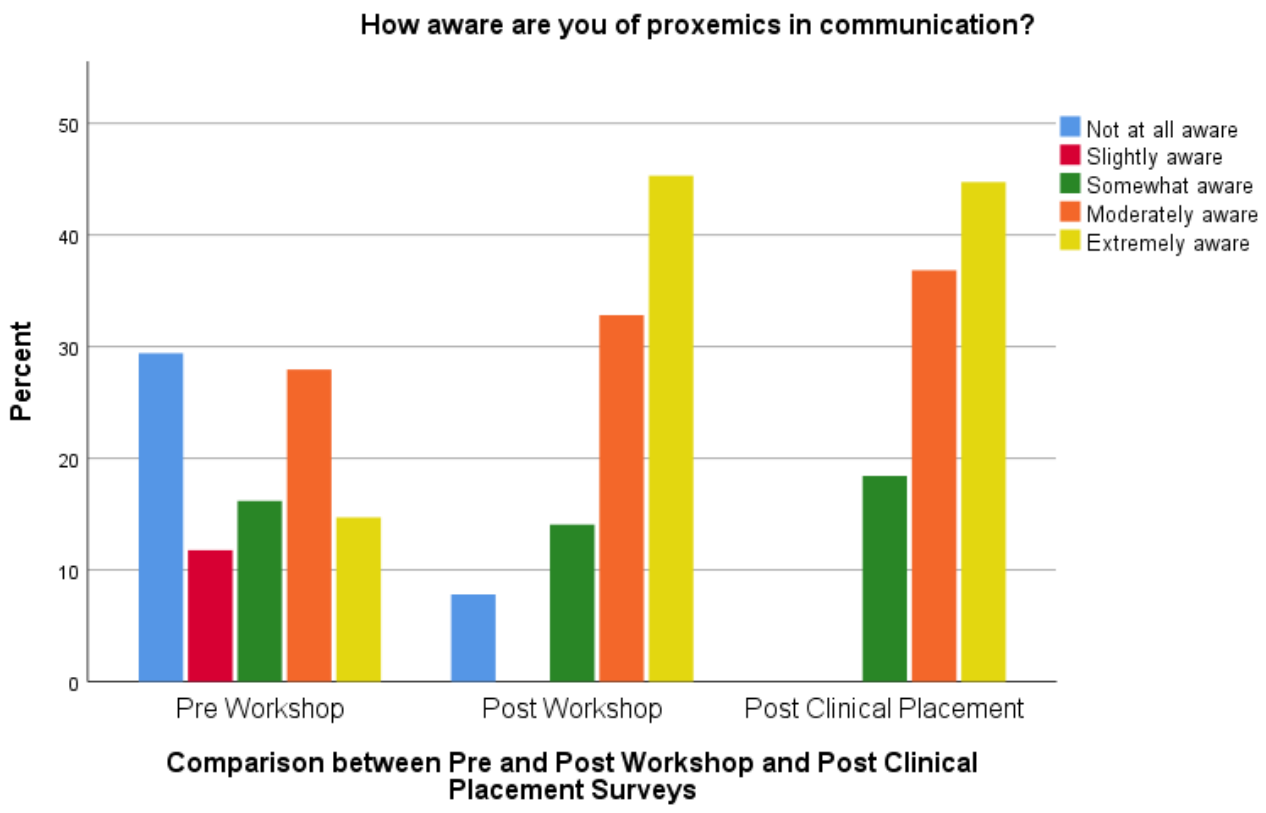

Figure 4: Self-evaluation results of midwifery student awareness of proxemics in the three surveys 
There was an increase in students self-rating of their knowledge across seven communication elements pre- and post- the workshop and again after their first clinical placement (figure 5).

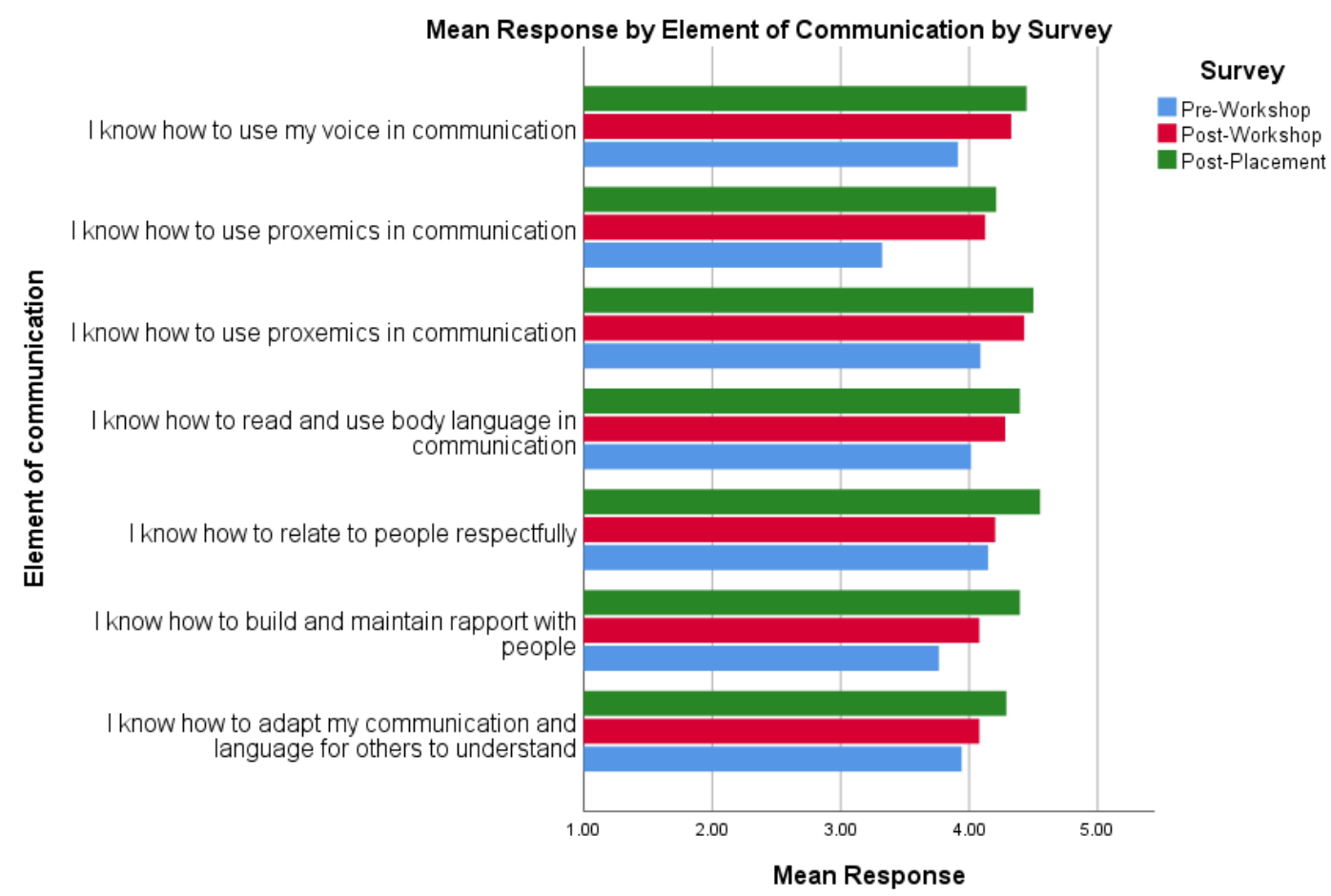

Figure 5: Self-evaluation results of midwifery student knowledge of Elements of Communication in the three surveys>

When examining the distribution of responses for each communication element, it was evident that the workshop prompted some students to be more critical of their skill mastery with respect to communication in clinical contexts. An example of this is the student self-evaluation of their capacity to relate to people respectfully (figure 6). Some students clearly reflected on their communication skills are realised that they were not always being respectful, with some selecting 'disagree' immediately after the workshop.

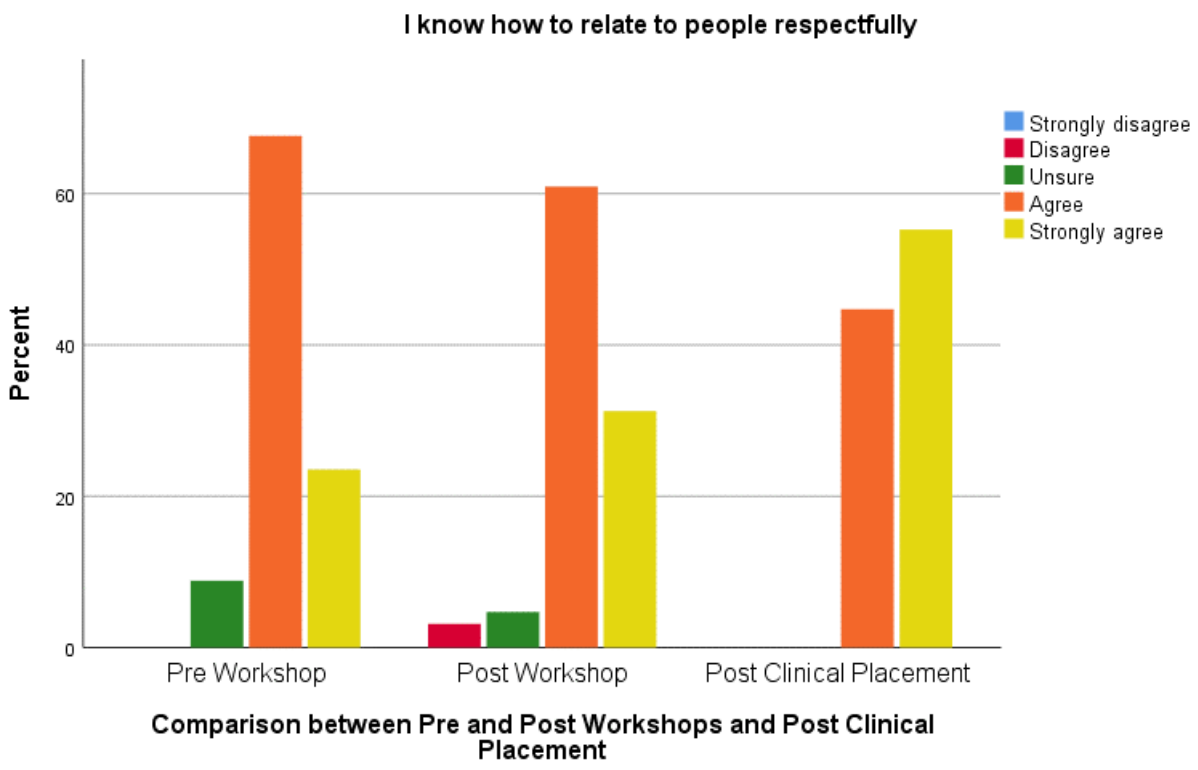

Figure 6: Comparison of midwifery student responses to their capacity to relate to people respectfully in the three surveys 
Students demonstrated the ability to be more critical of communicative exchange as the workshop progressed. Figure 7 is a typed reproduction of observations noted by two students on the provided rubrics during the final activity; the history-taking role plays. This reflects that students were more aware of the elements of communication and were able to articulate this by commenting on what was done well and not so well.

\begin{tabular}{|l|l|l|l|l|}
\hline Student & $\begin{array}{l}\text { Choice of words } \\
\text { and phrases }\end{array}$ & Reflective listening & Body Language & Voice \\
\hline Julia & $\begin{array}{l}\text { Carefully } \\
\text { considered } \\
\text { language } \\
\text { Polite }\end{array}$ & $\begin{array}{l}\text { Encouraging fillers } \\
\text { Clarifying and } \\
\text { seeking more } \\
\text { information }\end{array}$ & $\begin{array}{l}\text { Sitting at the same } \\
\text { level, close } \\
\text { Eye contact when } \\
\text { not writing } \\
\text { Open posture }\end{array}$ & $\begin{array}{l}\text { Soothing } \\
\text { Good volume }\end{array}$ \\
\hline Roma & $\begin{array}{l}\text { Polite } \\
\text { Both formal and } \\
\text { informal } \\
\text { Explained [terms] } \\
\text { when needed }\end{array}$ & Explained/educated & $\begin{array}{l}\text { Eye contact, faced } \\
\text { waman at the } \\
\text { samel } \\
\text { Sat to the side of } \\
\text { desk, not behind. }\end{array}$ & $\begin{array}{l}\text { Calm voice, } \\
\text { soothing, } \\
\text { reassuring }\end{array}$ \\
\hline
\end{tabular}

Figure 7: Example of two students' observations of another student roleplaying during the history-taking activity.

\section{Feedback From Both Teachers}

In interviews, the teachers made a number of observations and recommendations based on their use of the resources in the workshops. The results are summarised:

- The videos provided more options for interactive learning and class discussion.

- It is difficult to find Australian resources which reflect Australian culture and the Australian clinical context, so these are valuable for training.

- Having a staff member in the videos contributed to the engagement of the students.

- As the focus is on skills, a range of videos from different disciplines were also useful for teaching in the target discipline.

- Students were often more vocal and critical of the behaviours of the clinicians in the video than of their peers, which stimulated more discussion, and gave opportunities to teach them how to express criticism appropriately, focusing on the skills and not the person.

- There were observable differences in the students' use of clinical and general language, and their body language.

- The videos provided another option from staff roleplays when teaching about difficult clinical communication situations.

- In the future videos could be used to increase the robustness of the teaching of this area through linking the relevant videos to specific tasks and/ or assessments.

- The videos were an opportunity to set different assignments, such as the vignette, where students had to make a video on communication styles.

\section{DISCUSSION}

In this project, we evaluated the integration of digital video resources into student workshops for two different health disciplines, with both groups being at different levels of learning. The midwifery students had not yet experienced a clinical placement and their teacher was aiming to raise communication awareness. By contrast podiatry students had already experienced clinical placement and the focus on teaching was to improve their existing clinical skills to manage more complex situations. The teaching strategies for both groups were therefore different, but a common feature was that the teachers used scaffolded, explicit and staged approaches to develop student skills. Our videos were supported by learning packages, which deconstructed clinical communication into elements, with rubrics to help both teachers and students understand those elements. Different rubrics were also provided for different levels of learning.

The resources had a positive impact on student learning, with the videos, which were central to the learning activities, rated highly by both student groups as high for relevance, engagement, usefulness, improving confidence, and challenge. Midwifery students 
also indicated that after the workshop, they were more aware of and 'knew how to' use the elements of clinical communication. This was consistent with observations by the teachers who noted observable improvements in the students' abilities. It also appears that the communication skills learned in the workshop prepared the students for their first clinical placement, as after the placement these skills were maintained and even improved on. Student anxiety can be reduced and confidence increased in students who are well prepared for their clinical placement well-prepared students. ${ }^{13}$

The results of this study demonstrate that teaching resources for the teaching of clinical communication can be shared across different health disciplines, across different teaching practices, and for different stages of learning. Using videos as the core resource, activities can be tailored around the videos to align to the learning objectives of established curricula. Of note, both podiatry student and midwifery students rated the videos as very relevant, even though scenarios were used that demonstrated the communication behaviours of other health disciplines. This is important, as bespoke video resources are expensive and time consuming to create. The success in using the video resources was probably facilitated by having adaptable learning packages to support them. These videos and resources could also be potentially be used for inter-professional and multi-professional education and a broader suite could developed collaboratively across institutions that teach medical and health professionals.

A key element, in the teaching of both student groups, was the staging of the activities, with different resources introduced and used strategically to support and stimulate learning. The Foundation Quiz was used in both courses as a preliminary awarenessraising activity prior to the workshop, to generate discussion about the types of situations and dilemmas the students might encounter in clinical contexts. Similarly, the students were prepared for the video analysis and role plays with lower-stakes activities using the rubric, but this was approached differently in each course. In midwifery, as the workshop was for first-year students preparing for their first clinical placement, the preparation began with everyday communication, and progressed to the specific context and content of clinical communication. By contrast, as the podiatry students were in their third year of study, with experience of clinical placement and communication, so the video activity was used to (re-)calibrate the students' evaluation of clinical communication, which they then applied directly to the observation of and participation in clinical roleplays. The feedback from the midwifery students reflected an increase in appreciation of and confidence in the activities in the order in which the activities were organized, which suggests that the staging functioned as a scaffolding strategy for more complex tasks.

Role-play is widely used as an educational method for learning about communication in the health professions. ${ }^{14}$ Role-plays were used for teaching in both student groups. Role-plays between students are often used to simulate clinical communication interactions, however students may be reticent to provide critical feedback to their peers. The use of videos de-personalises the provision of feedback, and allows students to learn by watching, so they are in a better position prior to them being required to learn by doing. ${ }^{15}$

The project generated significant discussion by the teachers about how to extend the suite of resources. The short video format was noted as valuable, however one teacher suggested that longer videos covering full interviews or consultations would be useful also. This would demonstrate the holistic integration of different clinical communication skills through each phase of a consultation in order to reach an outcome. Teachers were particularly keen to see more videos in their discipline area, noting a lack of quality videos in areas like allied health and midwifery, compared with nursing and medicine. This indicates that despite this study demonstrating that clinical communication can be successfully taught across discipline areas, using examples from a variety of professional contexts, educators still seek to teach their students using examples from their own discipline.

The teachers also identified the potential value of student-generated resources, such as lists of useful expressions, and glossaries of terms to complement the institutional resources, and noted that video annotations made by the educator and/or the students could be harnessed to both create complementary resources, and improve the videos. The teachers found the lesson packs were too long, requiring too much time to both read and implement in limited class time, so they suggested short exemplar lesson plans, or 'two-pagers' outlining the key aims and uses of each resource. Finally, they suggested creating a database of examples of how resources had been used, for the use of other teachers.

\section{Limitations}

Although early data is positive, at this stage, only evaluations of the resources across two student groups have been conducted. The different teaching methods used for each group allowed only for generalized rather than detailed comparisons to be made. Also, the resources were integrated into face-to-face teaching, and their implementation in an online environment is an area of potential investigation. Further implementations across other disciplines and year levels are needed to determine the value of the resources as a whole-of-program approach. Longitudinal studies following different student a cohorts using these resources would be valuable.

(C) The Internet Journal of Allied Health Sciences and Practice, 2021 
We based our videos on only three communication skills which are not inclusive of all aspects of clinical communication. They were derived from a European communication framework made up of 61 skills. ${ }^{9}$ While the 3 skills provided a critical starting point, language and literacy specialists were concerned about validation of these and the other 58 skills, both by linguistic experts, and by the Australian health professional and educator community.

\section{CONCLUSIONS}

We have demonstrated that digital learning packages resources, based on videos, for teaching clinical communication skills can be adapted for use across different health professions. Students rated the resources high for relevance, engagement, usefulness, confidence and challenge, and led to improved self-ratings for knowledge and skills. These findings were supported by teacher observations. The sharing of digital resources to teach clinical communication across different health disciplines and institutions is possible, even when students vary by level, and different teaching methodologies are used. The flexibility, cross-disciplinary applications, digital format and examples of online applications of the resources are of particular relevance in the current higher education context, where face-to-face teaching may be compromised or cancelled.

\section{FUNDING AND CONFLICT OF INTEREST STATEMENT}

The project was funded through a Health Sciences Divisional Learning and Teaching Development Grant 2016-2017 and extension grant (2018). The authors declare no conflict of interest.

This work has not been published elsewhere and adheres to the Author Guidelines. All the authors have contributed to the paper, accept accountability for the accuracy and integrity of all aspects of the reported work, and agree to FoHPE copyright conditions.

\section{ETHICS APPROVAL}

Ethical approval was given under the University of South Australia's Human Research Ethics Committee Application ID: 0000036719 , prior to the commencement of the study.

\section{REFERENCES}

1. Leonard M., Graham S., Bonacum D. (2004). The human factor: the critical importance of effective teamwork and communication in providing safe care. Quality \& Safety in Health Care; Suppl 1: i85-i90.

2. Reader TW, Gillespie A, Roberts J. (2014). Patient complaints in healthcare systems: a systematic review and coding taxonomy. BMJ Quality \& Safety, May; 23, pp. 678-89.

3. Salas E., Goodwin G.F., Burke C.S. (2009). Team effectiveness in complex organizations. Cross-disciplinary perspectives and approaches. New York: Routledge/Taylor \& Francis Group.

4. Eggins, S. (Ed.), Slade, D. (Ed.), Geddes, F. (Ed.), et al. (2016). Effective Communication in Clinical Handover. From Research to Practice. Berlin, Boston: De Gruyter. Retrieved 24 Jul. 2020, from https://www.degruyter.com/view/product/433966.

5. NSQHS Standards. (2017). NSQHS Clinical Handover. [online] Available at: https://www.safetyandquality.gov.au/wpcontent/uploads/2012/01/NSQHS-Standards-Fact-Sheet-Standard-6.pdf [Accessed 24 July 2020].

6. Chipchase, L. S., Buttrum, P. J., Dunwoodie, R., Hill, A. E., Mandrusiak, A., \& Moran, M. (2012). Characteristics of student preparedness for clinical learning: clinical educator perspectives using the Delphi approach. BMC medical education, 12(1), 112.

7. Sealey R.M., Raymond J.G., Herb R., Rooney K., Crabb M., Watt K.. (2015). Supporting placement supervision in clinical exercise physiology. Asia-Pacific Journal of Cooperative Education, 16(1), pp. 53-69.

8. Bridgland A., Blanchard P. (2001). Flexible delivery/flexible learning... does it make a difference?. Australian Academic \& Research Libraries, 32 (3), pp.177-91.

9. Bachmann, C., Abramovitch, H., Barbu, C.G., Cavaco, A.M., Elorza, R.D., Haak, R., Loureiro, E., Ratajska, A., Silverman, J., Winterburn, S. (2013). A European consensus on learning objectives for a core communication curriculum in health care professions, Patient education and counseling 93, pp. 18-26.

10. Miller, G.E. (1990). The assessment of clinical skills/competence/performance. Academic medicine, 65.9 (1990): S63-7.

11. Krathwohl, D.R. (2002). 'A Revision of Bloom's Taxonomy: An Overview', Theory Into Practice, 41 (4), pp. 212-218, DOI: 10.1207/s15430421tip4104_2

12. University of South Australia (2018) Clinical Communication Resources [online] Available at https://lo.unisa.edu.au/course/view.php?id=9470 [Accessed 24 July 2020].

13. Chesser-Smyth P.A.(2005).The lived experiences of general student nurses on their first clinical placement: A 
phenomenological study. Nurse education in practice, 5(6):320-7.

14. Nestel, D., \& Tierney, T. (2007). Role-play for medical students learning about communication: guidelines for maximising benefits. BMC medical education, 7(1), 1-9.

15. He, G., Mackey, S., O'Brien, A., Ng, E. and Arthur, D., (2011). The use of video role play for teaching therapeutic communication skills. International Journal of Caring Sciences, 4(3), p.154.

\section{Appendix 1: Survey response data}

Table of survey responses by discipline

\begin{tabular}{|l|c|c|}
\hline \multicolumn{1}{|c|}{ Discipline } & $\begin{array}{c}\text { Response } \\
\text { percentage }\end{array}$ & Responses \\
\hline Physiotherapy & $36.07 \%$ & 22 \\
\hline Dietetics & $13.11 \%$ & 8 \\
\hline Occupational Therapy & $9.84 \%$ & 6 \\
\hline Medical Sonography & $8.20 \%$ & 5 \\
\hline Nursing & $6.56 \%$ & 4 \\
\hline Podiatry & $4.92 \%$ & 3 \\
\hline Midwifery & $4.92 \%$ & 3 \\
\hline Clinical Exercise Physiology & $4.92 \%$ & 3 \\
\hline Pharmacy & $3.28 \%$ & 2 \\
\hline Medical Radiations: Medical Imaging & $3.28 \%$ & 2 \\
\hline Medical Radiations: Nuclear Medicine & $1.64 \%$ & 1 \\
\hline Medical Radiations: Radiation Therapy & $1.64 \%$ & 1 \\
\hline Other & $2.28 \%$ & 2 \\
\hline Total respondents & & 62 \\
\hline
\end{tabular}

Table of respondents by role:

\begin{tabular}{|l|c|c|}
\hline \multicolumn{1}{|c|}{ Role } & $\begin{array}{c}\text { Response } \\
\text { percentage }\end{array}$ & Responses \\
\hline University lecturer & $58.62 \%$ & 34 \\
\hline Clinical educator & $36.21 \%$ & 21 \\
\hline Clinician & $41.38 \%$ & 24 \\
\hline Recent graduate (up to one year post-qualification) & $0.00 \%$ & 0 \\
\hline
\end{tabular}


Appendix 2: Scenario Descriptions

\begin{tabular}{|l|l|l|l|}
\hline $\begin{array}{l}\text { CLINICAL } \\
\text { INTERACTION PHASE }\end{array}$ & \multicolumn{3}{|l|}{ SCENARIO DESCRIPTIONS } \\
\hline $\begin{array}{l}\text { INITIATING } \\
\text { CONVERSATIONS }\end{array}$ & $\begin{array}{l}\text { Midwife undertaking a first } \\
\text { trimester internal exam on a } \\
\text { Kenyan woman who speaks } \\
\text { English as an Additional } \\
\text { Language, and is } \\
\text { accompanied by a partner for } \\
\text { support. }\end{array}$ & $\begin{array}{l}\text { Sonographer introducing } \\
\text { themselves to a child in order } \\
\text { to scan their hip }\end{array}$ & $\begin{array}{l}\text { Occupational Therapist in the } \\
\text { home of a disorientated and } \\
\text { confused client, with the } \\
\text { purpose of undertaking a } \\
\text { home assessment. }\end{array}$ \\
\hline $\begin{array}{l}\text { PROVIDING } \\
\text { INSTRUCTIONS }\end{array}$ & $\begin{array}{l}\text { Radiation Therapist } \\
\text { explaining a treatment to an } \\
\text { elderly man who has speech } \\
\text { deficit. }\end{array}$ & $\begin{array}{l}\text { Podiatrist providing foot ulcer } \\
\text { care to an Aboriginal man. }\end{array}$ & $\begin{array}{l}\text { Pharmacist clarifying a } \\
\text { prescribed medication. over } \\
\text { the counter to an elderly man } \\
\text { with a limited command of } \\
\text { English. }\end{array}$ \\
\hline $\begin{array}{l}\text { COMMUNICATION } \\
\text { DURING } \\
\text { PROCEDURES }\end{array}$ & $\begin{array}{l}\text { Radiographer positioning a } \\
\text { partially deaf person for a } \\
\text { shoulder x-ray }\end{array}$ & $\begin{array}{l}\text { Nurse assists a patient who } \\
\text { has had a recent operation to } \\
\text { the shower (disabled, and } \\
\text { pain a factor). }\end{array}$ & $\begin{array}{l}\text { Dietician performing PG SGA } \\
\text { on a Muslim patient who } \\
\text { requests her husband is with } \\
\text { her for the examination }\end{array}$ \\
\hline $\begin{array}{l}\text { CLOSING DOWN } \\
\text { CONVERSATIONS }\end{array}$ & $\begin{array}{l}\text { Physiotherapist closing off a } \\
\text { consultation while a 20-30 } \\
\text { year old male Australian is } \\
\text { getting off a treatment couch. }\end{array}$ & $\begin{array}{l}\text { Nuclear Medicine technologist } \\
\text { closing off an examination } \\
\text { (PET scan) with a patient who } \\
\text { is elderly and lonely and } \\
\text { wants to talk about her } \\
\text { deceased husband }\end{array}$ & $\begin{array}{l}\text { Exercise Physiologist closing } \\
\text { off an exercise plan with a } \\
\text { patient expressing frustration } \\
\text { and anger about the exercise } \\
\text { plan. }\end{array}$ \\
\hline
\end{tabular}




\section{Appendix 3: Foundation Quiz questions}

1. Mrs Jones is a 78-year-old lady who is attending the clinic you have been allocated to. You have been asked to explain to Mrs Jones that there will be a delay. When you start to explain this to Mrs Jones she starts to talk to you. Would you:

a. Allow Mrs Jones to talk and think about what you will say about the delay

b. Listen to what she has to say and tell her there is a delay

c. Tell her that there is a delay and then go back to your other tasks

d. Listen to what she has to say, respond the best you can and then explain the delay

Answer: $d$

You are a student in a busy clinic, and you have noticed a man in the waiting area is looking very unwell. You want to bring this to the attention of your supervisor. Which of the following statements demonstrates a ' direct approach' to this situation?

2.

a. Not everyone in the waiting area is looking well

b. Do you want me to assist people in the waiting area?

c. There is a man over there looking very unwell, should I ask him if he needs help?

d. Are you worried about anyone in the waiting area?

Answer: c

3. You are caring for a patient/client and have just explained a procedure that he will undergo. He appears confused. What approach could you use next?

a. Tell the patient/client that it will all be clear once the procedure commences

b. Try to understand what the problem is by going through the explanation again and check as you go through it

c. Think that the patient/client will understand once the patient/client has tried it a few times

Answer: $b$

d. Ask someone else to explain it to the patient/client.

4. You, as a student, are seeing a patient/client who has limited English language. You supervisor has asked you to explain to him that his first gym visit has been organised for this afternoon. Would you:

a. Write the information on a piece of paper

b. Introduce yourself to the patient/client, explain why you are there in clear and simple language

c. Speak to the nurse about the arrangements

d. As the patient/client has limited English language you decide not to talk to him as he will find out when someone comes to take him to the gym

Answer: $b$

5. The process of effective listening includes the following 'attending' and

a. Understanding and remembering

b. Writing notes and providing information

c. Explaining what was said and acting on this

d. Acknowledging and explaining your point of view.

Answer: a

6. Mrs $\mathrm{M}$ is a recent arrival to Australia. When you are explaining the test she will be undergoing she is avoiding eye contact with you. A possible reason for this could be

a. She is feeling embarrassed

b. Feels anxious about the situation

c. Cannot understand what you are saying

d. Any of the above

Answer: $d$ 
7. Nonverbal communication is part of effective communication. Which of the following statements related to nonverbal communication is most correct?

a. A person that smiles at you indicates he/she is happy to see you

b. Moving the head side to side always means 'NO'

c. A person who mirror's another person's posture can reflect empathy

d. None of the above

Answer: c

8. James is a 9-year-old boy attending the clinic with his mother for the first time. You would:

a. Clearly explain the procedure to him using the correct and specific medical terms

b. Use day to day language to explain what the procedure involves

c. Explain the procedure to his mother who will be able to explain it to James

d. Provide a very brief explanation, as it's a simple procedure and his mother or James can ask if they have any questions.

Answer: $b$

9. Mr A has been in hospital for over a week when you see him. This is your first placement and you have been asked by your supervisor to go through his history using a standard form. The most appropriate approach to this situation is:

a. To ask him whether he is happy and comfortable

b. Tell him that you have a form to complete and work through the form with him

c. Introduce yourself and explain why you are there and explain the form you would like to go through

d. Introduce yourself and leave the form with him to complete.

Answer: c

10. Being empathetic means one

a. Identifying with people's thoughts and feelings

b. Expressing feelings of sorrow for a person's distress

c. Telling the person you know exactly how he/she feels

d. Telling the person how you are feeling about this.

Answer: a

11. You are practicing your interviewing skills with Eddie, who is an international student. As you are preparing to start you notice that he is looking at the floor rather than at you. You think this could be possibly due to

a. Eddie being shy and uncomfortable

b. the gender difference between you

c. Eddie being uncomfortable about the interview topic

d. Any of the above

Answer: $d$

12. When communicating on a health-related issue with a person from an Aboriginal background it is important to

a. Consider their English language skills

b. Use gentle tones and not speak too fast

c. Ensure the interview is in a private area

d. All the above

Answer: $d$

13. Joanne is a 49-year-old Aboriginal woman from a country region. She has been admitted into hospital for an eye operation. Your supervisor has organised for you to interview Joanne so that you can practice your interview skills. The most appropriate approach when commencing the interview is to:

a. Use your standard interview plan and tell her what you will do

b. Use your standard interview plan and consider other specific questions you may wish to ask

c. Decide that this interview may be challenging for you and ask your supervisor for assistance 
d. Decide that you need to take a flexible approach and begin by taking some time to develop rapport with Joanne.

Answer: d

14. You are in a clinic with your supervisor and about to see the next patient/client. The clinic today has been very busy and there are several more patient/clients to see before lunch time. The patient/client that comes in appears angry and is rude to your supervisor about how long he's had to wait. Your supervisor tells the patient/client he will not continue with the consult and shows the patient/client out. You think through this situation and how you would approach it. You come to the conclusion that you would

a. Do the same as your supervisor and not tolerate such behaviour

b. Let the patient/client know you recognise he is angry and ask whether he would like to talk about it

c. Ignore the patient/client's anger and continue with the consult, as he is likely to calm down during the consult Answer: b

d. Respond in strong tone back as this could help control the patient/client.

15. Adel is a $27 y$ r old girl with head injuries that have resulted in some speech diffulties. She is attending the clinic for a scan. When you introduce yourself and are showing her through, she seems to be asking you a question, but you are not sure. The best approach for you to take is:

a. As it is a straightforward procedure and will only take a few minutes, you show her into the changing room and reassure her everything will be fine and there is no need to worry.

b. Tell her you can't understand what she is saying and she should talk to her doctor about any questions she has about the scan

c. Ask if she has a question for you and listen carefully to what she is saying and repeat the question to ensure you have interpreted it correctly

d. Tell her you will have time to discuss her question after the scan and direct her to the change room. Answer: c

16. Effective communication is important. Which of the following contributes towards optimising communication between a health professional and patient/client?

a. Sitting behind a desk to demonstrate your professional expertise, so the patient/client takes you seriously

b. Standing by a patient/client's bedside and telling them what he/she needs to do

c. Sitting by a patient/client's bed so you are at the same level while you are discussing their treatment.

d. None of the above

Answer: c

17. The use of a 'loud voice' may mean that a person is:
a. Feeling insecure
b. Angry
c. Relaxed
d. Tired

Answer: b

18. When initiating a conversation with a new patient/client who is in hospital it is best to:

a. Introduce yourself, explain why you are seeing the patient/client and ensure he/she is happy to continue with the session

b. Tell the patient/client why you are seeing him/her and as time is limited commence the procedure you needed to do

c. As patient/clients in hospital see so many health professionals they are used to having things done to them and therefore the best approach is to do what you need to do as efficiently as possible.

d. All the above, depending upon how busy you are at the time.

Answer: a 
19. You are coming to the end of your session with Mandy, who is 10 years old and with her parents. The most appropriate way to finish the interview is:

a. Say you would need to see Mandy again and direct the parents and Mandy to the reception desk to make another appointment.

b. Ask the parents whether they have any further questions and provide them with an appointment slip for the next appointment.

c. Ask Mandy and her parents whether they have any last questions and then summarise the main points, writing them down if necessary, before discussing a follow up appointment.

d. Let them know the session is now over and you would like to see Mandy again in 3 weeks.

Answer: c

20. You are interviewing a patient/client and they are describing some symptoms to you. What are the most likely verbal and non-verbal signs that he/she is feeling embarrassed or uncomfortable about describing them?

a. Furrowed brow, controlled voice, direct eye contact

b. High-pitched voice, averted body posture, keeping a distance between you

c. Flat or unsteady tone, drooped/hunched body posture, trembling lip

d. Pausing/hesitation, speaking quietly, looking around at other people nearby

Answer: $d$

21. If a patient/client is feeling embarrassed or uncomfortable during an interview, what is the most appropriate thing to do?

a. Help them to get over their embarrassment by encouraging them to laugh about it

b. Move closer to the patient/client, lower your voice and show empathy

c. Explain that embarrassment is unnecessary, as their symptoms are very common

d. Ignore it - because they are embarrassed, they probably want to get the interview over with Answer: $b$

22. Which of the following approaches to communication would establish the most appropriate relationship with a patient/client?

a. Reassure the patient/client that you are the expert by positioning yourself as a professional authority (e.g. behind a desk or counter)

b. Ensure the patient/client is influenced by important advice by adopting a standing position

c. Show the patient/client you want to involve them by positioning yourself on their level with no physical barriers in between

d. None of the above

Answer: c

23. Which of the following non-verbal signals does NOT convey that you are listening attentively to a patient/client?

a. Writing notes while the patient/client is talking?

b. Consistent eye contact

c. Regular nodding

d. Open body posture

Answer: a

(C) The Internet Journal of Allied Health Sciences and Practice, 2021 